Journal of Environmental Science and Public Health

doi: $10.26502 /$ jesph.96120036

Volume 2, Issue 4

Research Article

\title{
Remediation of Petroleum Hydrocarbons Contaminated Soil by Fenton's Oxidation
}

Sylvia Adipah*

Department of Environmental Engineering and Science, Chongqing University, Chongqing, China

*Corresponding Author: Sylvia Adipah, Department of Environmental Engineering and Science, Chongqing University, Chongqing 400044, China

Received: 30 October 2018; Accepted: 06 November 2018; Published: 16 November 2018

\begin{abstract}
The study was conducted by Fenton oxidation to efficiently remove contaminants from total petroleum hydrocarbon contaminated soil. IR spectrometry was used to determine the TPH level during soil treatments. In Fenton reaction, using hydrogen peroxide as the catalyst to produce hydroxyl radical could eliminate contaminant in a highly petroleum hydrocarbon contaminated soil. However, there is a need to use an appropriate quantity of reagent and $\mathrm{pH}$ (in the acidic medium) to obtain the most efficient in TPH removal in Fenton's oxidation. In this study, Fenton reaction could remove TPH in soil contaminated approximately; $48 \%$ within 2 hours with the optimal condition of $\mathrm{H}_{2} \mathrm{O}_{2}: \mathrm{Fe}^{2+}$ molar ratio of 104 , Fenton's reagent dosage of $50 \mathrm{ml}$, liquid/soil weight ratio of 15 and under a temperature of $25^{\circ} \mathrm{C}$. This indicated that Fenton's oxidation could be applied to clean up TPH contaminated soils within a short possible time.
\end{abstract}

Keywords: Petroleum Hydrocarbons (PHCs); Contaminated Soil; Chemical Oxidation; Fenton's Oxidation; Influential Factor

\section{Introduction}

\subsection{Description of TPHs contaminated soil}

According to the U.S.A Environmental Protection Agency (USEPA), Total petroleum hydrocarbons (TPH) is a term used to describe hydrocarbon compounds derived from petroleum sources. In this regard, TPHs are a mixture of chemicals. They are called hydrocarbons because almost all of them are made up entirely from hydrogen and 
carbon. According to Regenesis Bioremediation Products, most products that contain TPH are light colored liquids that evaporate easily and others are thick, dark liquids or semi-solids that do not evaporate easily [1]. Many of these products have gasoline, kerosene, and oily odors. Because modern society uses so many petroleum based products such as gasoline, kerosene, mineral oil, and asphalt, contamination of the environment by them are widely spread. Contaminations caused by these petroleum products contain a variety of hydrocarbons [1]. TPH released into the soil may move through the soil to the underground water and be trapped as vapor within the soil in the unsaturated zone. Due to adverse health effects, soil contamination with petroleum products create widespread environmental problems and it is becoming difficult to assess contamination in some sites to remediate and monitor these cleaning processes and evaluate final quality of the soil. TPH is an important group of environmental contaminants that are toxic to human and environmental receptors and can cause safety hazards, ecological harm and human health effects. Chemical oxidation remediation methods are one of the most effective and competitive technologies for the treatment of contaminated soils.

\subsection{Methods of remediating oil contaminated soil}

Remediation consists of actions on the soil aimed at the removal, control, containment or reduction of contaminants so that the contaminated site, taking account of its current use and approved future use, no longer poses any significant risk to human health or the environment. Enormous effort has been made to find efficient and effective ways to remediate petroleum contamination in soil, since increased attention has been paid for developing innovative technology for cleaning up these contaminants [2]. The conventional methods used in remediating petroleum hydrocarbons contaminated soil are broadly divided into physical, chemical and biological methods [2, 3] but the most common conventional method for the remediating of contaminated soil is excavation followed by land filling or incineration [4], due to limitations and drawbacks of these methods thus causing secondary pollution that might pose a long treat to the environment. Common Exposure Pathways at Petroleum-Contaminated Sites is explained in Table 1 .

\begin{tabular}{|l|l|}
\hline Contaminated Sites & Exposure Pathway \\
\hline Soil & $\begin{array}{l}\text { Direct contact by residents; leaching to underlying groundwater or nearby surface water; } \\
\text { runoff/erosion into nearby surface water, direct contact by plants and animals; migration } \\
\text { of vapors into overlying structures. }\end{array}$ \\
\hline Groundwater & $\begin{array}{l}\text { Drinking water use; migration of vapors into overlying structures; discharge to surface } \\
\text { waters. }\end{array}$ \\
\hline Surface water & $\begin{array}{l}\text { Contact by persons and aquatic organisms with contaminated sediments and surface } \\
\text { water; consumption of fish, shellfish and other aquatic organisms. }\end{array}$ \\
\hline Air/Vapor & Breathing vapor by workers/residents; exposure to utility workers. \\
\hline
\end{tabular}

Table 1: Common Exposure Pathways at Petroleum-Contaminated Sites. 
Technologies such as bioremediation, soil vapor extraction, soil washing, thermal treatment and chemical oxidation have been developed $[2,3]$ for treating contaminated soil. Contaminants can be treated either by in-situ or ex-situ [5]. In-situ remediation requires treating the contaminated material in place while ex-situ involves the physical removal of the soil and contaminants from the polluted site to be treated elsewhere [6].

\section{Experimental Study on Fenton's Oxidation in Remediating TPHs Contaminated Soil}

2.1 Introduction of Fenton's oxidation

Chemical oxidation treatment using Fenton will be of its significant. The main research objective is to indicate whether Fenton's oxidation technology can treat petroleum hydrocarbon contaminated soils within a short treatment period and how its influential factors can affect the remediation of TPH contaminated soil. It is of great significance to achieve the feasibility of using chemical method as efficient, cost effective and sustainable way to remediate petroleum hydrocarbon contaminated soils (PHCs) and treatment within a short limited time. The Fenton-like process generates hydroxyl radical, $\mathrm{OH}$, when the catalyst reacts with hydrogen peroxide. The hydroxyl radical is a strong oxidant and has an oxidizing potential of $2.8 \mathrm{eV}$ that degrade a variety of environmental contaminants at fast rate. The principal chemical reaction of Fenton-like process is provided below

$\mathrm{H}_{2} \mathrm{O}_{2}+\mathrm{Fe}^{2+} \rightarrow \mathrm{OH} \cdot+\mathrm{OH}-+\mathrm{Fe}^{3+}$

The initiation reaction described in equation 1 produces hydroxyl radical oxidants, the Fenton-like process produces superoxide radical $\left(\mathrm{O}_{2 .-}\right)$ and hydroperoxide anion $\left(\mathrm{HO}_{2}-\right)$ reductants in Equ. 1 and Equ. 5 [7]. The perhydroxyl radical $\left(\mathrm{HO}_{2} \cdot\right)$ is known to be a weaker reductant as compared to superoxide radical $\left(\mathrm{O}_{2 .-}\right)$ and hydroperoxide $\left(\mathrm{HO}_{2}-\right)$ anions (as shown in table 2).

\begin{tabular}{|l|l|l|}
\hline Names of chemicals & Chemical formula & Purity Quotient \\
\hline Carbon tetrachloride & $\mathrm{CCl}_{4}$ & IR \\
\hline Hydrogen peroxide & $\mathrm{H}_{2} \mathrm{O}_{2}$ & AR \\
\hline Sodium hydroxide & $\mathrm{NaOH}$ & AR \\
\hline Iron(ii) Sulfate hepta hydrate & $\mathrm{FeSO}_{4} \cdot 7 \mathrm{H}_{2} \mathrm{O}$ & AR \\
\hline Citric acid & $\mathrm{C}_{6} \mathrm{H}_{8} \mathrm{O}_{7} \cdot \mathrm{H}_{2} \mathrm{O}$ & AR \\
\hline Hydrochloric acid & $\mathrm{HCl}$ & AR \\
\hline Calcium chloride & $\mathrm{CaCl}_{2}$ & AR \\
\hline
\end{tabular}

Table 2: Chemicals list.

$$
\begin{aligned}
& \mathrm{H}_{2} \mathrm{O}_{2}+\mathrm{OH} \cdot \rightarrow \mathrm{HO}_{2} \cdot+\mathrm{H}_{2} \mathrm{O} \\
& \mathrm{HO}_{2} \cdot \rightarrow \mathrm{H}++\mathrm{O}_{2 \cdot \cdot^{-}} \\
& \mathrm{HO}_{2} \cdot+\mathrm{O}_{2 \cdot} \cdot \rightarrow \mathrm{HO}_{2^{-}}+\mathrm{O}_{2}
\end{aligned}
$$


$\mathrm{HO}_{2} \cdot+\mathrm{Fe}^{2+} \rightarrow \mathrm{HO}_{2^{-}}+\mathrm{Fe}^{3+}$

The strength of hydrogen peroxide increases as a result of adding Hydrogen peroxide $\left(\mathrm{H}_{2} \mathrm{O}_{2}\right)$ as an oxidant with ferrous iron $\left(\mathrm{Fe}^{2+}\right)$ salt as a catalyst.

\section{Materials and Methods}

\subsection{Soil description}

The soil was contaminated by petroleum hydrocarbon and it presented grey and black in color and was collected at Shapingba District, Chongqing city. At the sampling site the brown sandy soil beneath 1.5 meters was also contaminated and had an awful smell. Initially the soil was air dried at room temperature for about 3days and sieved using the mesh of $2 \mathrm{~mm}$ to remove the large particles. Prepared samples were contaminated by diesel. Original concentration of TPH was 7017 ppm (Parts per million) $\mathrm{HCl}, \mathrm{NaOH}, \mathrm{CCl}_{4}, \mathrm{Fe}^{2+}, \mathrm{H}_{2} \mathrm{O}_{2}$ and deionized water were mostly used throughout the experiments.

\subsection{Research plan}

The experiment took 5 factors into consideration, thus reaction time, $\mathrm{pH}$, and molar ratio of $\mathrm{H}_{2} \mathrm{O}_{2}$ : $\mathrm{Fe}^{2+}$, water/Fenton ratio and liquid/soil values and the specific introduction will be described in the following.

\subsubsection{Preparation of chemicals}

3.2.1.1 $\mathrm{Fe}^{2+}$ solution: $2.0 \mathrm{~g} \mathrm{FeSO}_{4} \cdot 7 \mathrm{H}_{2} \mathrm{O}, 48 \mathrm{~g}$ citric acid (solid), $22 \mathrm{~g} \mathrm{CaCl}_{2}$ was weighed using the Mettler Toledo (AL204), mixed in a beaker with deionized water and transferred into a $100.00 \mathrm{~mL}$ volumetric flask. Adding deionized water to the tick mark and the molar concentration calculated was 1.

3.2.1.2 $\mathrm{H}_{2} \mathrm{O}_{2}: 23 \mathrm{Ml}$ of $\mathrm{H}_{2} \mathrm{O}_{2}\left(30 \%, \rho=1.11 \mathrm{~g} \mathrm{~mL}^{-1}\right)$ was placed into a volumetric flask $(100 \mathrm{~mL})$ and water deionized was added to the tick mark. The molar concentration of $\mathrm{H}_{2} \mathrm{O}_{2}$ was $7.5 \mathrm{~mol} \mathrm{~L}^{-1}$.

\subsubsection{Effects of TPH contaminated soil}

3.2.2.1 Time: Total volume of the prepared solution was $150 \mathrm{ml} \mathrm{L}^{-1}$, Fenton's reagent dosage $50 \mathrm{~mL}$, Liquid: soil weight ratio was 15 , Molar ratio of $\mathrm{H}_{2} \mathrm{O}_{2}: \mathrm{Fe}^{2+}$ was 104 and $\mathrm{pH}$ was 7.5 . The reactor was run for 5, 10, 20, 30, 60, 120,240 and $480 \mathrm{mins}$ respectively under $25^{\circ} \mathrm{C}$, and samples were collected for analysis of TPH.

\begin{tabular}{|l|l|}
\hline TPH (average) & $7071 \mathrm{mg} / \mathrm{kg}$ \\
\hline pH & 7.5 \\
\hline
\end{tabular}

Table 3: Original concentration of TPH and $\mathrm{pH}$ of the contaminated soil. 
3.2.2.2 $\mathrm{pH}$ : Total volume of the prepared solution was $150 \mathrm{mg} \mathrm{L}^{-1}$. Fenton's reagent was $50 \mathrm{~mL}$, liquid/solid weight ratio was 15 , Molar ratio of $\mathrm{H}_{2} \mathrm{O}_{2}: \mathrm{Fe}^{2+}$ was $104 ; \mathrm{pH}$ was adjusted to $3.3,4.3,5.1$ and 6.1 respectively. The reactor was run for $120 \mathrm{mins}$.

3.2.2.3 Molar ratio of $\mathrm{H}_{2} \mathrm{O}_{2}: \mathrm{Fe}^{2+}$ : Total volume was $150 \mathrm{mg} \mathrm{L} \mathrm{L}^{-1}$, pH was 3.12, Fenton's dosage was $50 \mathrm{ml}$. liquid/soil weight ratio was 15 , Molar ratio of $\mathrm{H}_{2} \mathrm{O}_{2}: \mathrm{Fe}^{2+}$ was adjusted among 104, 156, 202 and 330. The reactor was run for $120 \mathrm{mins}$.

3.2.2.4 Fenton's dosage: Total volume of the prepared solution was $150 \mathrm{mg} \mathrm{L}^{-1}$, $\mathrm{pH}$ was 3.12 , liquid/solid weight ratio was 15 , Molar ratio of $\mathrm{H}_{2} \mathrm{O}_{2}: \mathrm{Fe}^{2+}$ was 330 and the reactor was run for 120 mins. Fenton's reagent dosage was adjusted among $75 \mathrm{ml}, 50 \mathrm{ml}, 37.5 \mathrm{ml}$ and $30 \mathrm{ml}$.

3.2.2.5 Liquid/Soil: Total volume of the prepared solution was $150 \mathrm{ml}, \mathrm{pH}$ was 3.12, molar ratio of $\mathrm{H}_{2} \mathrm{O}_{2}: \mathrm{Fe}^{2+}$ was 330 , Fenton's reagent dosage was $50 \mathrm{ml}$ and liquid/solid weight ratio was 5, 10, 15 and 20. The reactor was run for 120 mins.

\subsection{Analytical methods}

3.3.1 Determination of TPH: TPH determination was based on Soil determination of petroleum oil content by infrared spectrometry (Environmental protection standard for China OIL (8 (H.J 201). $5 \mathrm{~g}$ of soil was weighed in a beaker after drying. $20 \mathrm{ml}$ of $\mathrm{CCl}_{4}$ (IR) was pipetted and added to the soil and placed in a reactor and oscillated for 30mins. It was then filtered with an aerator filtrator and the liquid was extracted. $5 \mathrm{~g}$ of magnesium metasilicate was added to each liquid in a $150 \mathrm{ml}$ conical flask and oscillated for 30mins and filtered again into a $50 \mathrm{ml}$ volumetric tube. Drop of $\mathrm{CCl}_{4}$ (IR) was added to reach its tick mark. It was shaken upwards and downwards to have an even mixture. The liquid sample was then poured into a seal and placed in an IR spectrometer to determine its TPH level. The formula below was used to calculate the efficiency of TPH removal and its influential factors where $\mathrm{x} 1$ is the initial content of TPH, $\mathrm{x} 2$ is the final content of TPH. $(\mathrm{x} 1-\mathrm{x} 2) / \mathrm{x} 1=\mathrm{TPH}$ removal.

3.3.2 Determination of $\mathrm{pH}: 10 \mathrm{~g}$ contaminated soil weighed and mixed with $100 \mathrm{ml}$ of deionized water into a beaker and oscillated for 30 minutes, $\mathrm{HCl}$ and $\mathrm{NaOH}$ was then added to adjust the $\mathrm{pH}$ of the slurry. $\mathrm{PH}$ meter was used to measure the level of $\mathrm{pH}$ in the slurry.

3.3.3 Determination of aqueous Fe: A standard stock solution of iron was prepared and placed into a $150 \mathrm{ml}$ conical flask and two glass pearls were added under heat to reduce the solution to $15 \mathrm{ml}$. It is then allowed to cool under room temperature and was transfer into a $50 \mathrm{ml}$ tube. Saturated sodium acetate was added and a piece of Congo red litmus paper was placed into it and the paper turned red in color. Phenanthroline and deionized water was added to reach its peak mark. It was then placed into a $10 \mathrm{ml}$ of cuvette to measure the absorbency of the solution using absorption spectroscopy under $510 \mathrm{~nm}$ and a standard curve was achieved. 


\section{Results and Discussion}

The aim of the research was to use Fenton's oxidation to determine the TPH removal efficiency in the contaminated soil. The contaminant removal in the soil analyzed was found to be dependent on the treatment time, dosage of Fenton, molar ratio of hydrogen peroxide to ferrous, $\mathrm{pH}$ and ratio of liquid to soil. The Figures below presents the effect of the parameters treatment on the removal of TPH in the contaminated soil analyzed. The TPH removal efficiency was measured using the IR spectrometer (OIL 8 (GB/T16488-1996)).

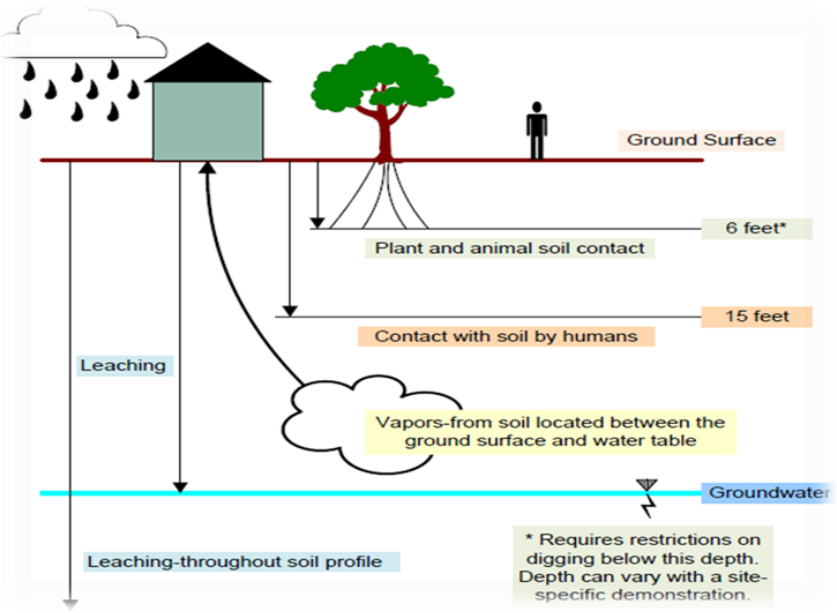

Figure 1: Soil points of compliance for various exposure pathways [8].

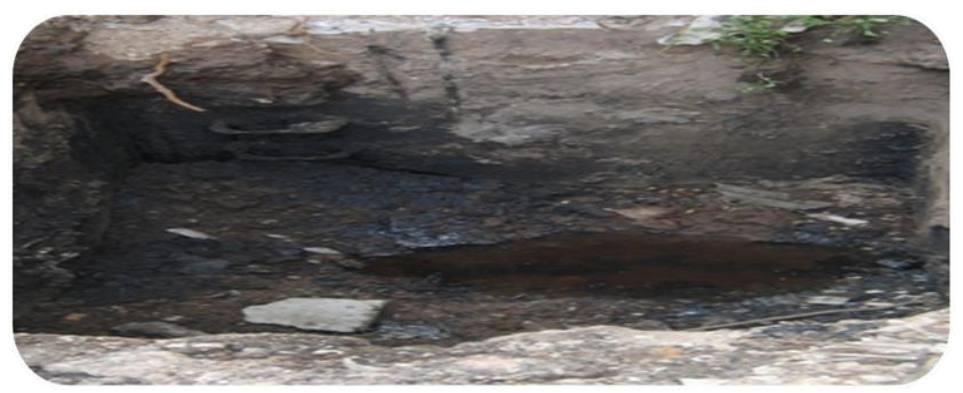

Figure 2: Petroleum hydrocarbons contaminated soil beneath 1.5 meters.

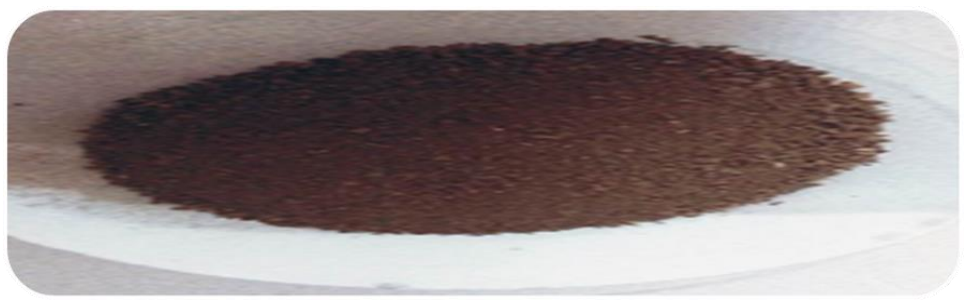

Figure 3A: Contaminated soil before treatment. 


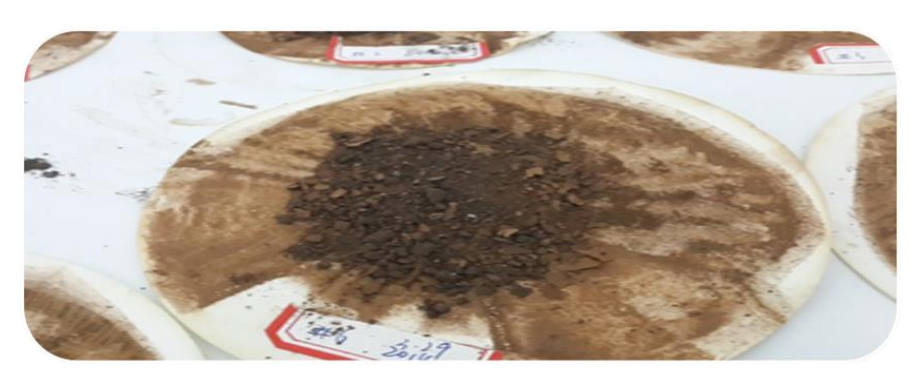

Figure 3B: Contaminated soil after treatment.

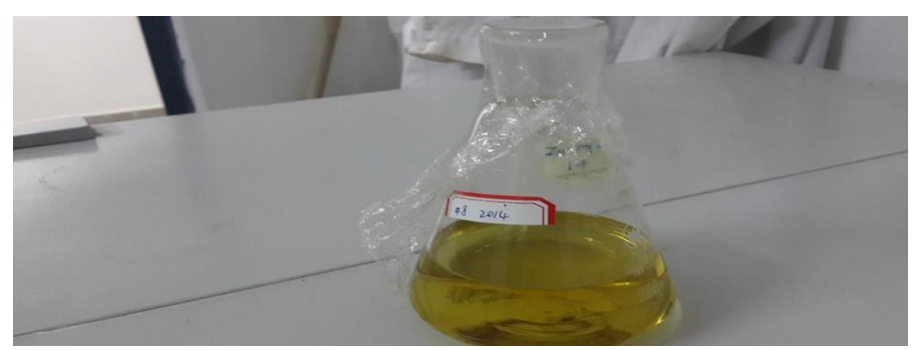

Figure 4: Liquid extracted from the contaminated soil containing ferrous iron.

\subsection{Effect of time on TPH removal efficiency}

The experiment for the rate of removal was tested based on the optimum process conditions determined above $\mathrm{pH}$ is 7.5, molar ratio of $\mathrm{H}_{2} \mathrm{O}_{2}: \mathrm{Fe}^{2+}$ of 104 , Fenton's reagent dosage of $50 \mathrm{ml}$ and liquid/solid ratio of 15 under a temperature of $25^{\circ} \mathrm{C}$. It was found that the rate of TPH removal increased rapidly (after adding Fenton reagent and shaking the sample) from the initial time of $5 \mathrm{mins}$ to $10 \mathrm{mins}$ in the removal efficiency of TPH. There was increase in time until about $60 \mathrm{~min}$ were the removal rate became steep and steady with gradual increase from $240 \mathrm{mins}$ to 480mins. TPH removal percentage was achieved within 2 hours of reaction time. A steady state of $\mathrm{OH}$ concentration was attained as Fenton reaction started (Figure 5).

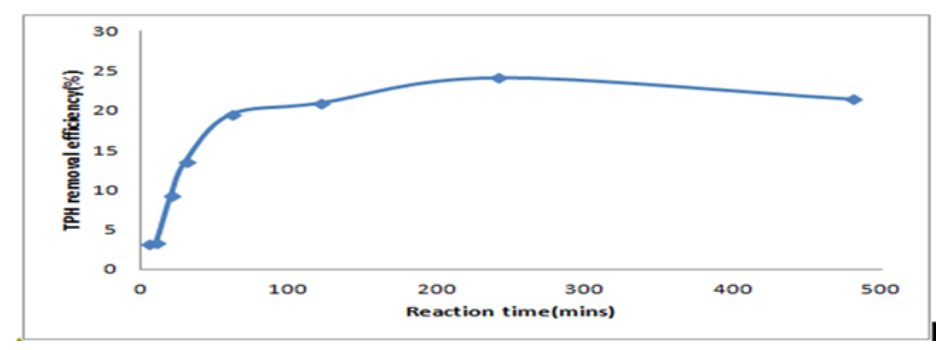

Figure 5: the results of TPH removal efficiency with different reaction time.

\subsection{Effects of pH on TPH removal efficiency}

This aspect was carried out based on the following conditions time of $120 \mathrm{~min}, \mathrm{H}_{2} \mathrm{O}_{2}: \mathrm{Fe}^{2+}$ molar ratio of 104, Fenton's reagent dosage of $50 \mathrm{ml}$, and liquid/soil weight ratio of 15 and different $\mathrm{pH}$ of 3.3, 4.3, 5.1 and 6.1 respectively. The results of the $\mathrm{pH}$ test condition demonstrated that the most effective removal was at $\mathrm{pH} 3$ with percentage removal of approximately $37 \%$. From the Figure 6, the effect of $\mathrm{pH}$ seemed to be less effective in TPH 
removal at high $\mathrm{pH}$. At higher $\mathrm{pH}$ the removal was quite high (pH of 3 to $\mathrm{pH}$ of 5) (Figure 6). With decreasing $\mathrm{pH}$, the percentage TPH removal dropped linearly from 5 to 3 . The reaction slowed down due to the formation of ferrichydroxo complexes and the decomposition of $\mathrm{H}_{2} \mathrm{O}_{2}$. The Fenton's reagent needs acid to produce $\cdot \mathrm{OH}$ hydroxyl radicals. The result shows that ferrous iron could react with $\mathrm{H}_{2} \mathrm{O}_{2}$ efficiently under acidic conditions. Thus $\mathrm{pH}$ of 3 is the optimum for the TPH contaminated soil treated by Fenton oxidation.

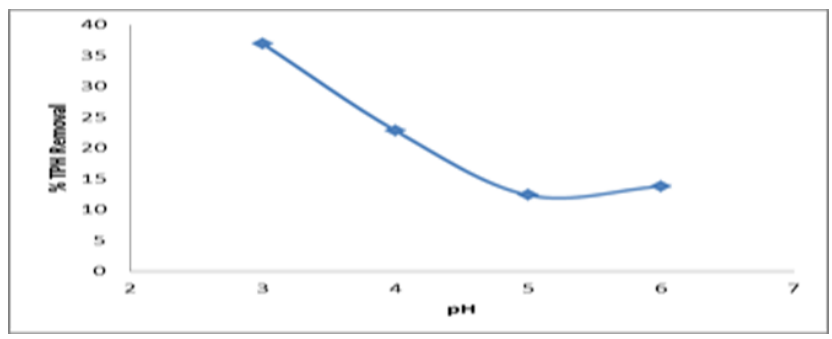

Figure 6: Effect of $\mathrm{pH}$ on TPH removal efficiency.

\subsection{Effect of the molar ratio of $\mathrm{H}_{2} \mathrm{O}_{2}$ to $\mathrm{Fe}^{2+}$ in Fenton reagent on TPH removal efficiency}

The aspect was based on the following conditions: $\mathrm{pH}$ 3.1, reaction time $120 \mathrm{mins}, \mathrm{H}_{2} \mathrm{O}_{2}: \mathrm{Fe}^{2+}$ molar ratio of 104, 156, 202 and 330 respectively and liquid/soil ratio of 15. The removal of TPH in the molar ratio of $\mathrm{H}_{2} \mathrm{O}_{2}: \mathrm{Fe}^{2+}$ test is presented in Figure 7. The optimum condition of the TPH removal efficiency was obtained at the molar ratio of 330:1 (removal efficiency of 48\%) and the lowest level of removal efficiency was recorded when the molar ratio of $\mathrm{H}_{2} \mathrm{O}_{2}: \mathrm{Fe}^{2+}$ was 104:1 (removal efficiency of 37\%). Similar trend was observed by Lu et al. [9]. From molar ratio of 202:1 to 330:1 at pH of 3.1, the TPH removal was gradual and this indicated that the optimal treatment condition in removal of residual contaminants in petroleum contaminated soil by Fenton-like oxidation was at a molar ratio of $\mathrm{H}_{2} \mathrm{O}_{2}: \mathrm{Fe}^{2+}$ of 330:1 and at optimum $\mathrm{pH}$ of 3.1. With the addition of catalyst, TPH removal in soil contaminated depended on the treatment time, a manner of hydrogen peroxide application. A stepwise addition of $\mathrm{H}_{2} \mathrm{O}_{2}$ and the increasing of the treatment time were more effective for the removal of TPH in the contaminated soil than the addition of $\mathrm{H}_{2} \mathrm{O}_{2}$ at once without several treatment times. A slow addition of $\mathrm{H}_{2} \mathrm{O}_{2}$ to the system with excess iron provides conditions that minimizing quenching of $\mathrm{OH}$ radicals [9]. The addition of catalyst $\mathrm{H}_{2} \mathrm{O}_{2}$ did improve the removal percent of TPH contaminated soil as Figure 7.

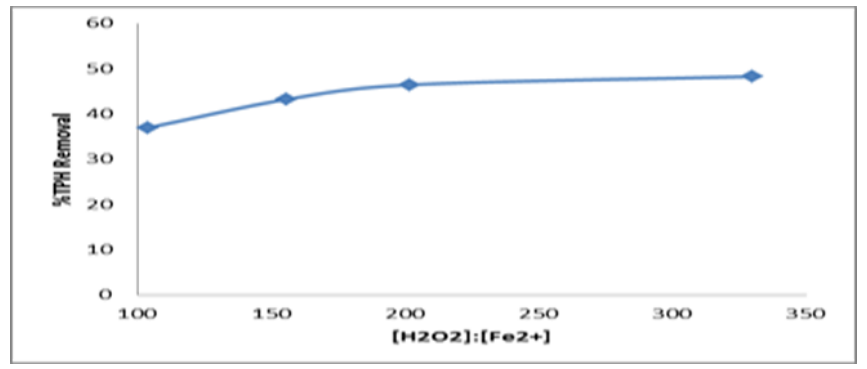

Figure 7: Effect of the molar ratio of $\mathrm{H}_{2} \mathrm{O}_{2}$ to $\mathrm{Fe}^{2+}$ in Fenton reagent on TPH removal efficiency. 


\subsection{Effect of Fenton's dosage on TPH removal efficiency}

This aspects was based on $\mathrm{pH}$ (3.12), reaction time (120mins), molar ratio of $\mathrm{H}_{2} \mathrm{O}_{2}: \mathrm{Fe}^{2+}$ (330:1), and Fenton's dosage adjustment at $75 \mathrm{ml}, 50 \mathrm{ml}, 37.5 \mathrm{ml}$ and $30 \mathrm{ml}$. With respect to the dosage of hydrogen peroxide there was a change in the degradation of petroleum hydrocarbons. High dosage of $\mathrm{H}_{2} \mathrm{O}_{2}$ is a remarkable source for -OH production as shown in Figure 8. After a significant increase in removal efficiency, there was a steady change, thus after adding more volume of hydrogen peroxide. With increasing dosage of $\mathrm{H}_{2} \mathrm{O}_{2}$, there was an increased in the removal of TPH in the contaminated soil. While $\mathrm{H}_{2} \mathrm{O}_{2}$ dosage was further elevated; TPH removal did increase much significantly. Moreover, inorganic reactants can also consume $\mathrm{H}_{2} \mathrm{O}_{2}$.

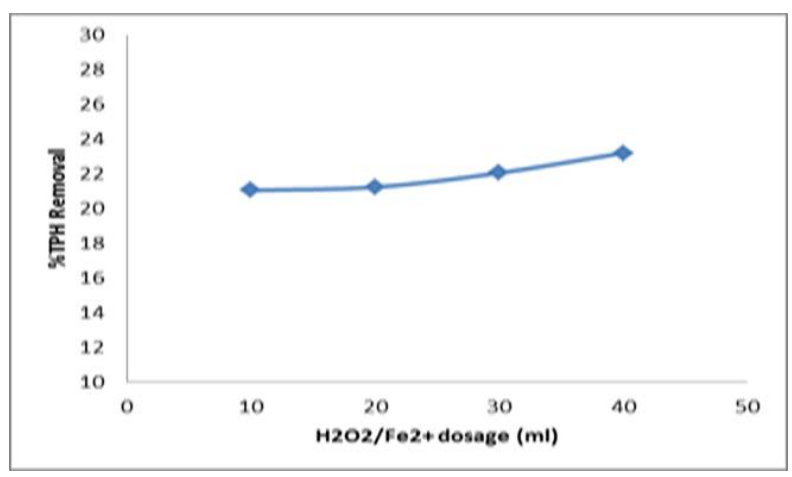

Figure 8: Effect of Fenton dosage on TPH removal.

\subsection{Effect of liquid to soil ratio on TPH removal}

Total volume was $150 \mathrm{mg} \mathrm{L}^{-1}$, pH was 3.12, molar ratio of $\mathrm{H}_{2} \mathrm{O}_{2}: \mathrm{Fe}^{2+}$ was 330 , Fenton's reagent dosage was $50 \mathrm{ml}$ and liquid/solid weight ratio was 5, 10, 15 and 20. The reactor ran for 120mins.In this experiments liquid to soil ratio was taken into consideration to remediate TPH efficiency. The liquid to soil ratio ranges from 5 to 20 and the more addition of Fenton's reagent resulted in a steady removal of TPH efficiency of 19 to $28 \%$ (Figure 9).

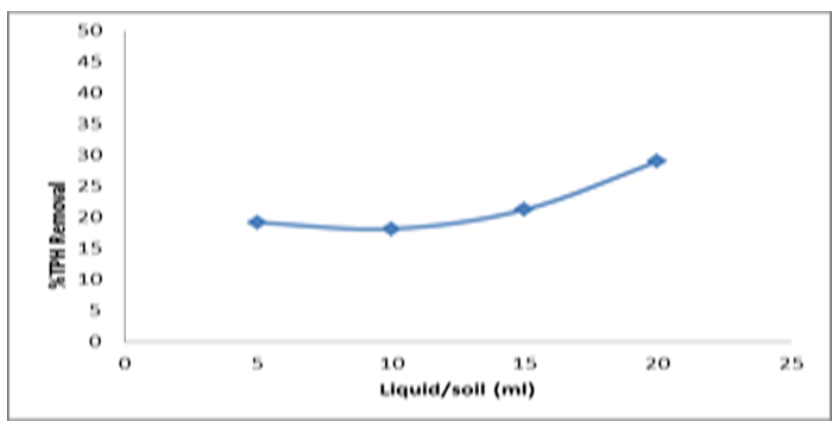

Figure 9: Effect of liquid to soil ratio on TPH removal efficiency.

With the increase in liquid to soil ratio from 5 to 20, there was no significant effect on TPH removal efficiency. This reveals that soil washing with water only is not an effective treatment measure for the remediation of the contaminated soil. Because the soil contains contaminants that are strongly sorbed onto soil particles and cannot be 
washed away, thoroughly purely soil washing using water as the washing agent. Oxidant addition is a necessity to effectively remove and oxidize the adsorbed organic contaminants.

\begin{tabular}{|l|l|l|l|}
\hline No. & Name of Equipment & Type & Manufacturers \\
\hline 1 & Oscillator & WSZ-100A China & Shanghai \\
\hline 2 & Infrared Spectrometer & Oil 8 & Qingdao, China \\
\hline 3 & Balance & Mettler Toledo & Shanghai, China \\
\hline 4 & pH meter & AL204 Mettler Toledo & Shanghai, China \\
\hline 5 & Deionizer & UPT-II-10T & Chengdu, China \\
\hline 6 & Vacuum pump & ANB 2005 & Baoding, China \\
\hline 7 & Loft drier & DJR-250-II & Chengdu, China \\
\hline
\end{tabular}

Table 4: Lists of the apparatus used in remediating TPH contaminated soil.

\section{Conclusion}

This study reported the capability of a Fenton reaction, using hydrogen peroxide catalyst to produce hydroxyl radical. From the study, Fenton reaction using hydrogen peroxide catalyst could eliminate contaminant in a highly petroleum hydrocarbon contaminated soil. However, there is a need to use an appropriate quantity of reagent and $\mathrm{pH}$ (in the acidic medium) to obtain the most efficiency in TPH removal in Fenton's oxidation. At the optimum condition, Fenton reaction could remove TPH in soil contaminated approximately $48 \%$ within 2 hours, $\mathrm{pH}$ of 3.12 , molar ratio of hydrogen peroxide to ferrous ions of 330, water/Fenton ratio of $50 \mathrm{ml}$ and liquid/soil of 15 . This indicates that Fenton's oxidation can be applied to clean up TPH contaminated soils within a short possible time.

\section{Acknowledgement}

I will like to thank Chongqing University for their great assistance and SER for allowing me to publish my paper successfully.

\section{References}

1. Regenesis Bioremediation Products. Principles of Chemical Oxidation Technology for the Remediation of Groundwater and Soil. Regenesis Inc, San Clemente, California, USA (2010).

2. Zhu X, Venosa AD, Suidan. Literature review of the use of commercial bioremediation agents for cleanup of oil-contaminated estuarine environments (2004).

3. Venny, Gan S, Ng HK. Inorganic chelated modified-Fenton treatment of polycyclic aromatic hydrocarbon (PAH) contaminated soil. Chemical Engineering 180 (2011): 1-8.

4. Shyang-Chyuan Fang, Shang-Lien Lo. Persulfate oxidation activated by peroxide with and without iron for remediation of soil contaminated by heavy fuel oil. Second International Conference on Mechanic, Automation and Control Engineering (2011). 
5. TEPA (Taiwan Environmental Protection Administration). Taiwan's Soil and Groundwater Pollution Remediation Act, Taipei, Taiwan (2010).

6. Kapley A, Purohi HJ. Genomic tools in bioremediation. Indian Journal of Microbiology 49 (2009): 108113. Lehr. Technologies with Abstracts and Technology Costs. Wileys Remediation Technologies Handbook (2004).

7. Yang Bo Ming, Chih Ming Kao, Chiu Wen Chen, et al. Application of In Situ Chemical Oxidation for the Remediation of TPH Contaminated Soils. Applied Mechanics and Materials 126 (2011): 196-200.

8. Boopathy R. Factors limiting bioremediation technologies. Bio resource Technology 74 (2000): 63-67.

9. Lu M. Remediation of petroleum-contaminated soil after composting by sequential treatment with Fentonlike oxidation and biodegradation. Bio resource Technology 101 (2010): 2106-2113.

10. De Laat J. Effects of chloride ions on the iron (III)-catalyzed decomposition of hydrogen peroxide and on the efficiency of the Fenton-like oxidation process. Applied Catalysis B, Environmental 66 (2006): 137146.

11. Fang Shyang Chyuan, Shang Lien Lo. Persulfate Oxidation Activated by Peroxide with and without Iron for Remediation of Soil Contaminated by Heavy Fuel Oil: Laboratory and Pilot-Scale Demonstrations. Applied Mechanics and Materials 126 (2011): 2546-2556.

12. Robert L Siegriest, Michelle Crimi, Richard A Brown. In-situ Chemical Oxidation for Groundwater Remediation. Springer (2011).

13. Speight JG. Introduction to Bioremediation. Bioremediation of Petroleum and Petroleum Products. Speight/Bioremediation (2012).

14. US. Environmental Protection Agency (USEPA), the Effects of Oil Spill in Aquatic Environments (2011).

15. Watts RJ, Sarasa J, Loge FJ, et al. Oxidative and reductive pathways in manganese catalyzed Fenton's reactions. J Environ Eng 131 (2005): 158-164.

Citation: Sylvia Adipah. Remediation of Petroleum Hydrocarbons Contaminated Soil by Fenton's Oxidation. Journal of Environmental Science and Public Health 2 (2018): 168-178.

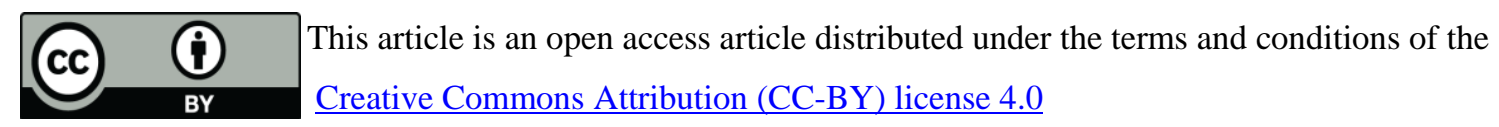

